drive to parasympathetic centers of the visceral brain.

\section{REFERENCES}

GELHORN, E. Prolegomena to a theory of the emotions. Perspectives in Biology, 1961, 4, 403.

GLICKMAN, S. E., \& SROGES, B. W. Curiosity in zoo animals. Behaviour, 1966, 26, 151 .

KARCZMAR, A. G., \& SCUDDER, C. L. Behavioral responses to drugs and brain catecholamine levels in mice of different strains and genera. Federation Proceedings, 1967, 26, 1186-1191.

LENNART, H., \& LARSON, K. Mating behavior of male rats after olfactory bulb lesions. Physiology and Behavior, 1967, 2, 207.

SCHMALTZ, E., \& ISAACSON, L. R. Effect of bilateral hippocampal destruction on the acquisition and extinction of an operant response. Physiology and Behavior, 1967, 2, 291-298.
SCUDDER, C. L., AVERY, D., \& KARCZMAR, A. G. Automated avoidance conditioning climbing screen. The Pharmacologist, 1965, 7, 154.

SCUDDER, C. L., AVERY, D., \& KARCZMAR, A. G. A study of avoidance conditioning in five genera of mice. Animal Behaviour, 1969, 17 , $77-86$.

SCUDDER, C. L. \& KARCZMAR, A. G. Neurochemical changes and aggression in different strains and genera of mice. Proceedings of the Midwest Regional Meeting of the American Psychiatric Association, in press.

STANLEY-JONES, D. The kybernetics of cyclothymia. Progress in Brain Research. In $\mathrm{N}$. Weiner \& J. P. Schadé (Eds.), Cybernetics of the Nervous System. New York: Elsevier, 1965. Pp. 151-169.

\section{NOTE}

1. This work was supported in part by Illinois Mental Health Grant No. 17-176.

\title{
Amphetamine depression of a multiple CRF-EXT operant schedule: A sex comparison'
}

\section{SHERWOOD O. COLE, Rutgers University, Camden, N.J. 08102}

\begin{abstract}
Amphetamine, $0.5 \mathrm{mg} / \mathrm{kg}$ administered on five successive trials, significantly depressed the operant performance of both male and female rats maintained on a multiple CRF-EXT schedule. That the depression of behavior was due to the drug was indicated by the recovery of performance in both sexes on two subsequent distilled water injection trials. Some basic sex differences in reaction to the reinforcement schedule also were observed on all trials of the study.
\end{abstract}

The depressant effect of amphe tamine on operant performance maintained by various reinforcement schedules is well established and has been reviewed elsewhere (Cole, 1967). However, some reversal effects of the drug have been noted with DRL schedules (Kelleher et al, 1961) and FR schedules with pre-time-out (Ferster et al, 1962).

In an operant task where 5-min periods of continuous reinforcement (CRF) and extinction (EXT) were successively alternated, the depressant effect of amphetamine in male albino rats has been found to hold for a $2.0 \mathrm{mg} / \mathrm{kg}$ dose (Cole, 1968). The present study was undertaken for the purpose of making a sex comparison of the depressant action of the drug on operant behavior maintained by a similar multiple CRF-EXT schedule while employing a smaller dose. Special attention was focused on the generality of such a depressant effect or its dependency on sex.

\section{SUBJECTS}

Sixteen albino rats (eight males and eight females), purchased from West Jersey Biological Supply, served as Ss. At the beginning of training, they were approximately 90 days old with an average body weight of $250 \mathrm{~g}$. The Ss were housed individually in a temperature-controlled laboratory and were allowed ad lib access to Purina chow and water in the home cages.

\section{PROCEDURE}

Initially, all Ss were trained in a standard commercial operant chamber (Gerbrands Co.) during 30-min CRF sessions under 48-h food deprivation. Training was continued until each $S$ had established a baseline operant rate, following which time, they were assigned to either a distilled water (DW) or amphetamine (AMP) group with the restriction that half of the males and half of the females were assigned to each group. Statistical analysis of the groups indicated no initial differences in operant rate due to sex or assignment.
All Ss then were given seven 30-min trials of multiple CRF-EXT schedule with 5 days between trials. On Trials 1-5, the Ss were food deprived for $\mathbf{4 8 ~ h}$ immediately prior to testing and then injected intramuscularly with DW or $0.5 \mathrm{mg} / \mathrm{kg}$ d-amphetamine sulfate $^{2} 15 \mathrm{~min}$ before placement in the apparatus. In the case of the DW groups, the Ss were administered a controlled-volume injection adjusted to body weight. Trials 6 and 7 served as "recovery-from-drug" trials with all Ss receiving DW injections $15 \mathrm{~min}$ before testing. In all other respects, Trials 6 and 7 were identical to the five preceding trials.

On all seven trials, the $30-\mathrm{min}$ test period was divided into 10 successively alternating 3-min periods of CRF and EXT. Half of the Ss under each of the four major experimental conditions (male-DW; male-0.5 AMP; female-DW; female-0.5 AMP) received the CRF, EXT, CRF, EXT, CRF, EXT, CRF, EXT, CRF, EXT sequence with the other half of the Ss receiving the EXT, CRF, EXT, CRF, EXT, CRF, EXT, CRF, EXT, CRF sequence. During the CRF periods, the $S$ received a single $45-\mathrm{mg}$ precision food pellet $^{3}$ for each bar press. A cue light, directly above the food tray, remained on for the entire CRF period but was off during EXT periods.

\section{RESULTS AND DISCUSSION}

The mean number of total bar presses for the four groups on the five drug and two "recovery-from-drug" trials is presented in Fig. 1. An overall trend analysis of the data on Trials 1.5 yielded a significant drug effect $(\mathrm{F}=15.44 ; \mathrm{df}=1 / 12 ; \mathrm{p}<.01)$ and $\mathrm{a}$ significant difference between sexes $(\mathrm{F}=6.15 ; \mathrm{df}=1 / 12 ; \mathrm{p}<.05$ ). Consistently higher average rates were observed in both female groups on Trials 1-5 when compared to their male counterparts (female-DW > male-DW; female-0.5 AMP $>$ male0.5 AMP). Analysis of Trials 6 and 7 indicated a complete recovery from drug effect $(F<1.00)$ on both sexes. Although not reaching statistical significance on the two "recovery-from-drug" trials, the average rates of the two female groups continued to be higher than those for the male groups.

In an attempt to ascertain possible differences in the depressant effect of the drug with sexes, further trend comparisons were made on Trials 1-5. Analysis indicated that the difference in trends of the female DW and 0.5 AMP groups was significant $(F=7.53 ; \mathrm{df}=1 / 6 ; \mathrm{p}<.05)$ and that the difference in the performance trends of the male DW and 0.5 AMP groups also was significant $(F=9.49 ; \mathrm{df}=1 / 6 ; \mathrm{p}<.05)$.

The results of the present study demonstrate the effectiveness of amphetamine $(0.5-\mathrm{mg} / \mathrm{kg}$ dose) in depressing the general operant performance of both male and female rats maintained on a multiple 


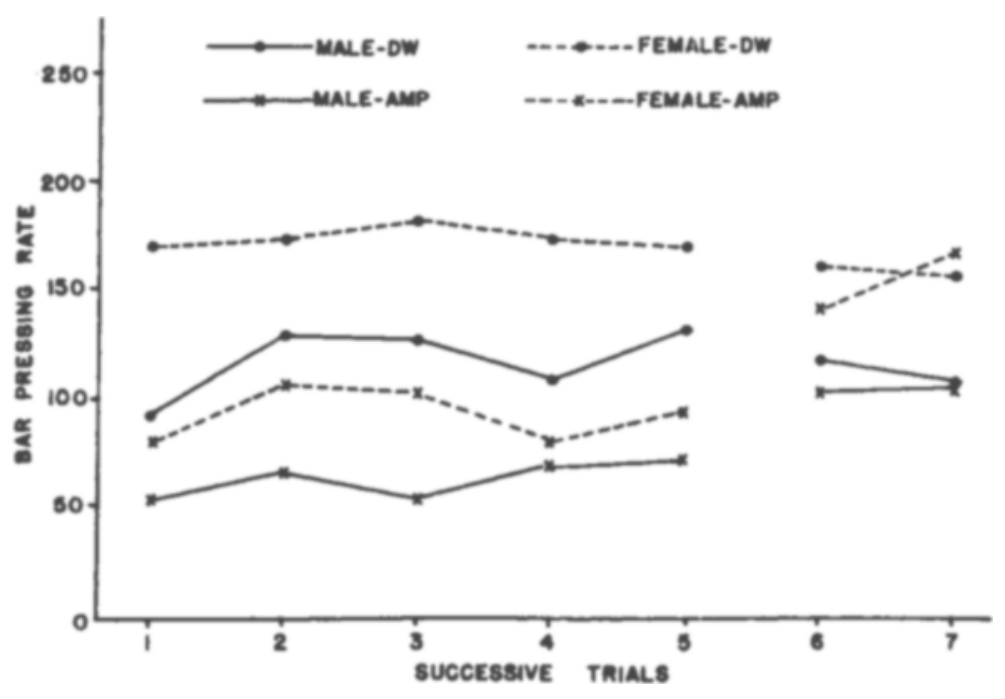

CRF-EXT schedule. That the depression of the performance in both sexes was due to the drug and not to other factors operating over trials is indicated clearly by the recovery of behavior on the two DW trials (see Trials 6 and 7 in Fig. 1).

The overall significant difference in the operant rate between sexes on Trials 1-5 (with drug conditions collapsed) strongly suggests that the male and female groups reacted differently to the present multiple CRF-EXT schedule. That the sex difference in rate was one of reaction to the reinforcement schedule and not a druginduced phenomenon is indicated clearly by the fact that the female DW group as well as the female AMP group consistently demonstrated higher average rates than the male counterpart group. The "recovery-fromdrug" data on Trials 6 and 7 also are consistent with this interpretation in that, after the Ss had recovered from the depressant effect of the drug, the female significant).
Fig. 1. Mean number of total bar presses for male and female DW and AMP groups on five drug and two "recovery-from-drug" trials.

difference in reaction to the total reinforcement program.

Additional experimentation needs to be conducted in order to determine under what other multiple reinforcement schedules and dose levels the depressant effect of amphetamine on operant performance holds for both sexes. Since it is quite possible that such a sex difference in reaction to reinforcement schedule as was observed in the present study may make it difficult to establish generalizations about the drug's action, it should be given special consideration in future sex-comparison experiments.

groups continued to respond at a higher average rate (although not statistically

Although it might seem logical to relate such a reactive difference of the males and females to a sex difference in discrimination between CRF and EXT periods, the findings do not support this view. No statistically significant difference in the percentage of responses made during the CRF periods of the five drug trials (measure of reinforcement discrimination) by the male and female groups was observed $(F<1.00)$ nor was a significant Sex by Drug interaction effect on the discrimination of such CRF periods present $(F=1.25 ;$ df $=1 / 12$; $\mathrm{p}>$.05). All four groups responded with a higher percenlage of responses during the CRF periods of the drug trials. Thus, the higher average rates of the female groups are not due to a sex difference in meeting the discriminatory requirements of the task, but rather, represent a more general sex

\section{REFERENCES}

COLE, S. O. Experimental effects of amphetamine: A review. Psychological Bulletin, 1967. 68, 81-90.

COLE, $S . O$. The depression of operant behavior and retarding action on discrimination learning by amphetamine. Psychonomic Science, 1968. 10, 19-20.

FERSTER, C. B., APPEL, J.B., \& HISS, R. A. The effect of drugs on a fixed-ratio performance suppressed by a pre-time-out stimulus. Journal of the Experimental Analysis of Behavior, 1962 , $5,73-88$.

KELLEHER, R. T., FRY, W., DEEGAN, J., \& COOK, L. Effects of meprobamate on operant behavior of rats. Journal of Pharmacology \& Experimental Therapeutics, 1961, 133, 271-280.

\section{NOTES}

1. Appreciation is expressed to Miss Karen Weidel and Miss Mary Lou Didamo for their assistance in data collection.

2. Supplied by Smith, Kline, and French Laboratories, Philadelphia, $\mathrm{Pa}$.

3. Purchased from the P. J. Noyes Co., Lancaster, N.H. 